Article

\title{
Enhancing Online Patient Support through Health-Care Knowledge in Online Health Communities: A Descriptive Study
}

\author{
Donghua Chen ${ }^{1} \mathbb{B}^{\mathbb{D}}$, Runtong Zhang ${ }^{1, *(\mathbb{D})}$, Kecheng Liu ${ }^{2}$ and Lei Hou ${ }^{2}$ \\ 1 Department of Information Management, School of Economics and Management, \\ Beijing Jiaotong University, Beijing 100044, China; 15113181@bjtu.edu.cn \\ 2 Henley Business School, University of Reading, Reading RG6 6UD, UK; k.liu@reading.ac.uk (K.L.); \\ 1.hou@pgr.reading.ac.uk (L.H.) \\ * Correspondence: rtzhang@bjtu.edu.cn; Tel.: +86-010-51683854
}

Received: 29 June 2018; Accepted: 4 August 2018; Published: 6 August 2018

\begin{abstract}
Online health communities (OHCs) should utilize health-care knowledge for enhancing online patient support. To examine the use of existing OHCs to identify the challenges and strategies of enhancing online patients' decision-making support, we conducted a descriptive study to evaluate the information availability, user availability and knowledge usability in 100 carefully-selected health-related websites. On the basis of criteria for effective OHCs, we used three evaluation instruments for health-care professionals to review and score the websites. Questionnaire results were examined from the perspective of information, user and knowledge support. Results corroborate that over $80 \%$ of the websites facilitate effective social functions, whereas only $33 \%$ provide health-care decision-making services to online patients. Approximately $46 \%$ of them satisfy four or five effective OHCs' criteria. Three of them only offer the functions of patients' charts and journals to support health data management. Although the existing OHCs are facilitated with good social interaction and support, only a few can assist patients in making effective health-care decisions, not to mention properly using health-care knowledge support.
\end{abstract}

Keywords: health-care knowledge; online health communities; online patient support; evaluation instrument; descriptive study

\section{Introduction}

Online systems have emerged as important channels by which traditional industries provide services [1]. Given their convenience, many online health communities (OHCs) have been established for patients, especially those who suffer from chronic diseases [2-4]. These OHCs integrate social network services to help patients understand and improve their conditions at any place and time [5]. Moreover, OHCs help enhance the abilities of chronic patients to seek useful social support from OHCs and aid in protecting patients from medical information overload [6]. Most online patients use the Internet as a source of effective health-care information [7]. However, despite the development of Internet-based services, individuals commonly fail to obtain useful health information related to their illness in OHCs. The reason is that most health-related websites emphasize providing pure news and social functions, rather than decision-making support for patients with health-care knowledge, thereby negatively affecting their personal health [8]. Therefore, studies on effective social and knowledge-based support in OHCs are crucial to online patients' well-being and overall quality of life [9].

Online patients differ from offline patients physiologically and psychologically [10]. Generally, offline patients seek medical instructions from medical professionals from hospitals or clinics, 
whereas online patients commonly go online for health information that can improve their health conditions in their daily lives [11]. For instance, chronic patients perpetually suffer from low self-esteem, which negatively affects their daily lives. They must increase their levels of self-care, well-being and disease management to cope with their illness [12]. A study confirmed that social support is an important factor affecting the psychology of human immunodeficiency virus/acquired immune deficiency syndrome and chronic patients [13]. In another work, patients with chronic lymphocytic leukaemia manifested were affirmed to have increased distress and anxiety or depressive symptoms when coping with high symptom burden and low social support [14]. Chronic disorders, such as mental disorders, also increase the burden on patients and caregivers [15]. Health literacy is also important to patient health. For instance, individuals with low health literacy may achieve high eHealth literacy scores. Thus, these individuals may use non-established criteria assessing the quality of online health information heavily [16]. Thus, one must firstly understand the natural characteristics of online patients to achieve effective and lasting treatment for patients with chronic diseases [17].

The proper use of OHCs may greatly influence patients' social behaviours and actions. For instance, in Type 1 diabetes, psychosocial and behavioural factors, including low social support, low generic quality of life and difficulties in managing diabetes, are associated with high emotional burden [18]. Medication-related problems have five broad categories, including: side effects; medicine use; cognitive, practical and sensory problems; lack of information or understanding; and problems with access to and organization of services [19]. OHCs provide chronic patients with patient coaching and self-management support to help nurses play an intensified role in alleviating patients' health conditions [20]. The impacts of these strategies on chronic patients' lives can be observed from patients' personal relationships, work abilities and social interactions. These patients' usage of medical knowledge on their illness provides a community with further policies and treatment strategies for properly managing chronic diseases [21].

This study addresses three questions related to OHCs by conducting a descriptive study on 100 carefully-selected health-related websites. The three questions are as follows:

- How do existing OHCs influence information availability for online patients?

- How do existing OHCs facilitate social services for online patient support?

- How does domain knowledge in health-care enhance existing OHCs?

On the basis of these questions, this study aims to examine information availability, user availability and knowledge usability of 100 health-related websites by developing three evaluation instruments for reviewing websites. Section 2 proposes criteria for selecting proper health-related websites and provides evaluation instruments for evaluating the websites in a review process. Section 3 illustrates the results collected from the review process. Thereafter, we identify the challenges for and discuss the proper strategies of applying health-care knowledge support for online patients in Section 4. Finally, we conclude our work in Section 5.

\section{Materials and Methods}

We initially determine the measurements for effective OHCs and accordingly propose the criteria of selecting 100 existing health-related OHCs in Table S1 in the Supplementary Materials for investigation and evaluation. Subsequently, we develop our evaluation instruments to conduct a descriptive study of investigating 100 health-related websites for our study objectives.

\subsection{Criteria for Selecting $\mathrm{OHCS}$}

Before examining relevant websites, they should satisfy the study's standards and criteria in terms of the general characteristics of OHCs. Thus, a list of OHCs from a mainstream site-ranking website is selected on the basis of the criteria in Box 1 .

Many health-related websites provide substantial useful medical information, such as news and blogs, to online users. Few of these websites are established on a social platform that enables online 
patients to interact with one another. Thus, we initially select 100 different health-related websites that can be regarded as typical OHCs. The selection process is required to fulfil the exclusion criteria in Box 2.

Box 1. Inclusion criteria for selecting online health communities (OHCs) to meet the needs of online patients.

(1) The OHC must be built upon a social platform that supports interaction among online patients.

(2) The OHC must present a brief introduction of biomedical and health-care knowledge relevant to patients' conditions, treatments and symptoms.

(3) The OHC must utilize recommendation mechanisms for similar patients and posts.

(4) The OHC must provide an open subscription network that aids online users to explore other online patients with similar conditions.

(5) The OHC must allow online patients to find information on other patients and doctors.

(6) The OHC's health services must include publication of health-related announcement, news, warnings and reports.

(7) The OHC must assist online patients in decision making regarding their treatment and enhancement of health lifestyle.

(8) The OHC must show patients' charts and journals.

(9) The OHC must provide the summarized data of patient-reported outcomes for similar patients' reference.

Box 2. Exclusion criteria for selecting OHCs to study.

(1) Sites that merely introduce a health-related product for specific companies.

(2) Sites with content that is irrelevant to humans.

(3) Sites that do not allow users to interact with health service providers or other users.

(4) Sites run by specific governments and other non-profit organizations that only publish information resources.

(5) Sites that show excessive commercial advertising and pricing.

(6) Sites resembling libraries for mere educational purposes.

(7) Sites that do not provide a user account or only offer a subscription panel.

We select 100 websites roughly in the first step; thus, certain websites that do not meet the criteria for $\mathrm{OHC}$ selection may be included in further evaluation. Therefore, these sites are excluded in subsequent steps to ensure that the selected websites are valid for a study of social and knowledge usability among OHCs.

To understand the current development of OHCs further and help us implement our instruments to evaluate the effectiveness of OHCs, we carefully select 100 health-related websites as a sample for our descriptive study. This selection is based on the reputation and popularity of the websites to make sure the sample is a good representation. Figure 1 shows the distribution of the sources of these 100 health-related websites. These sources include Google, Wikipedia, Alexa and Baidu; thus, the authoritative references of selecting proper health-related sites are provided in this study. Figure 2 presents the topics of our selected websites, $24 \%$ of which are comprehensive. 


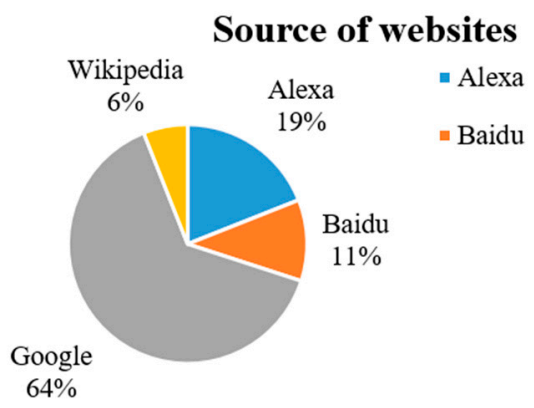

Figure 1. Distribution of sources among 100 health-related websites.

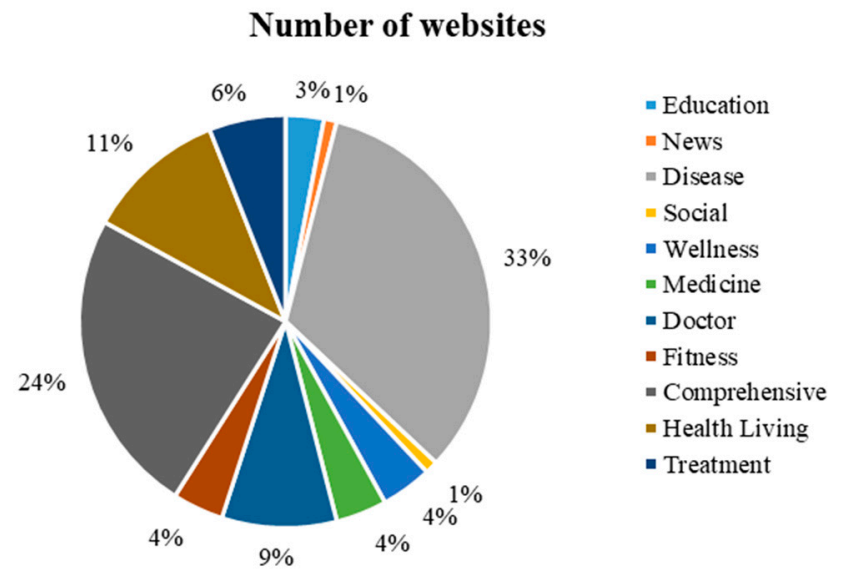

Figure 2. Distribution of topics among 100 health-related websites.

\subsection{Evaluation Instruments}

To improve the assessment of online health information used in OHCs, a study suggested that increased attention should be devoted to identifying different criteria for patients and developing shared definitions and measures for the most commonly-used outcomes in evaluating online health information [22]. The Department of Health and Human Services' Office of Disease Prevention and Health Promotion in the United States of America conducted a nationwide assessment of the quality of web-based health information by using the objectives of Healthy People 2020's Health Communication and Health Information Technology (HC/HIT). The institution provided standardized objectives of HC/HIT-8.1 and HC/HIT-8.2 for defining and measuring the quality of health websites. This process of quality evaluation is a critical first step for assessing the quality of websites for the professional design, development and management of health-related websites [23].

On the basis of HC/HIT-8.1 and HC/HIT-8.2, 100 health-related OHCs are investigated to explore information availability, user availability and knowledge usability fully in health-related websites using the following evaluation instruments.

\subsubsection{Evaluation of Information Availability of Websites}

In this step, we adopt the website information reliability instrument from HC/HIT-8.1 to evaluate information availability that satisfies the least requirement for OHCs. This tool helps evaluate whether health-related websites are eligible for information use by patients in a process. For the selected 100 health-related websites, we implement this evaluation instrument to initially evaluate websites' information availability. We also add the questions from Boxes 1 and 2 to the instruments. 


\subsubsection{Evaluation of the User Availability of Websites}

We evaluate the additional aspects and qualifications of the selected health-related websites in terms of user availability. To achieve this goal, we employed the website usability evaluation instrument by scoring with HC/HIT-8.2 to evaluate the user availability of the websites and study how existing OHCs influence online patients through user-centred functions, such as commenting and sharing.

\subsubsection{Evaluation of Knowledge Usability of Websites}

In related work, the question "How knowledge support is exchanged in social network of OHCs" has been raised [24]. Biomedical domain knowledge has already greatly influenced research on clinical decision support in hospitals [25]. Moreover, biomedical knowledge in OHCs can be widely used in subscription networks among patients. Such knowledge provides an observational environment for monitoring drug usage and its consequences [26]. Most data in OHCs are patient-reported outcomes, which have shown great value in improving OHC services. However, knowledge from outcomes may be unreliable and may lead online patients to inappropriate medical treatments. Certain $\mathrm{OHC}$ services also consider weak social connections among patients only based on the analyses of the limited information from patient profiles (e.g., name, city, main condition and symptom) [27]. Thus, biomedical and health-care domain knowledge affects not only patients' social preferences, but also the establishment of social relations in health-related websites.

Barriers to the access and use of online health information can cause poor knowledge usability of eHealth services. Thus, mobile applications hold great potential for eHealth and mHealth services catering to individuals of low health literacy [28]. The complexity of factors influencing health literacy necessitates interdisciplinary approaches for recognizing and developing appropriate interventions [29]. Although participants possess adequate health and eHealth literacy, they rely excessively on search engine results to guide their search of online health information. Notably, no significant relation has been observed between health and eHealth literacy [30]. The evaluation approaches of online health information with multiple assessment tools and involving quantitative and qualitative observations can optimize assessment strategies. Health-care providers are important for shared decision-making with patients on the latter's health through effective communication regardless of other factors [31].

Considering the investigation results of HC/HIT-8.1 and HC/HIT-8.2, we design an instrument (see Supplementary Materials) that evaluates the quality of interaction between social network and domain knowledge used in OHCs. Given the study of the websites, we arrive at our conclusions and discuss our results.

\subsection{Review Process}

The selected 100 health-related websites are reviewed by 10 reviewers with experience of working on health informatics, which ensures the quality of website evaluation. The instrument requires participants to possess a thorough knowledge of online health information, especially the third instrument used to evaluate health-care knowledge usability. The steps of the detailed review procedure are as follows:

Step 1: We invite a group of researchers from our team to review the 100 websites.

Step 2: We introduce the objectives of this study and present the general characteristics of six typical OHCs to reviewers such that they have a full understanding of what good OHCs are like.

Step 3: Reviewers are required to be familiar with the criteria of evaluating OHCs from our research.

Step 4: Reviewers start to review the websites by filling in the three evaluation instruments. Each site is evaluated at least twice from different reviewers. 
Step 5: Two reviewers screen each website independently. In case disagreements occur, a third reviewer can be appointed to resolve the eventual discussion.

Step 6: We collect the results of the evaluation using the three instruments and analyse the obtained results.

This review procedure is designed to minimize the errors of evaluation to ensure the representativeness of our descriptive study.

\section{Results}

In total, we have collected 200 questionnaire results for Evaluation Instrument 1, 200 question results for Evaluation Instrument 2 and 363 questionnaires for Evaluation Instrument 3 . Descriptive statistics was used to analyse the obtained data. We examined implicit results from the three aspects of the health-related websites, namely information availability, user availability and knowledge usability.

\subsection{Overview of Existing $\mathrm{OHCS}$}

With the rapid expansion of OHCs, medical professionals who lack sufficient expertise in health-care knowledge cannot handle several needs of online chronic patients [32]. A study asserted that analysing the level of patient empowerment and its effects on physician-patient management may improve patients' decision-making ability [33]. The mere provision of comprehensive medical knowledge to online patients by such medical experts is not the best way to promote the future development of OHCs [34].

We selected six typical OHCs according to the definition of OHCs in Wikipedia [35] in terms of four aspects to explore how knowledge support is utilized in these OHCs. These OHCs were PatientsLikeMe, HealthBoards, MedHelp, DailyStrength, WebMed and HealthUnlocked. The four aspects were functional module, subscription network, individual patient and user interaction. Functional modules refer to theme-based pages that solve specific problems in health-care. The subscription network is the user interaction model that allows users to interact within the sites. Such a study suggested that these communities lack sufficient implementation given the health-care knowledge in social interaction. Table 1 presents an overview of the investigation results.

Most websites were facilitated by user accounts to allow online patients to personally manage their health data. However, these OHCs differed in their manners of helping patients share personal experiences with one another. In PatientsLikeMe, most health data were highly structured. OHCs allow patients to review other patients' journals and charts freely in OHCs' subscription network. HealthBoards contains a drug-based forum that enables patients to share their experiences of drug use. However, posts in the forum are mostly written in natural language. MedHelp hosts symptom-based communities for patients to discuss relevant topics and for doctors from hospitals and medical research institutions to respond to online discussion boards. DailyStrength serves as a social network that focuses on support groups. Online patients can provide emotional support to other patients by discussing personal struggles and successes. WebMD is well known for delivering trustworthy and timely health-related news. It provides credible health information, supportive communities and in-depth reference materials on health subjects. HealthUnlocked uses health-specific artificial intelligence to help patients thoroughly manage their own health by recommending relevant and tailored health content, information and services. The site enables peer support for various health conditions and promotes patient empowerment by actively engaging individuals to lead their own health-care. In summary, most OHCs are established on the basis of the basic patient social network and limited expert knowledge (e.g., disorder list), which can provide the foundation for supporting patient-centred networks. 
Table 1. Summary of the usage of health-care knowledge in six typical OHCs.

\begin{tabular}{|c|c|c|c|c|}
\hline OHC & In Functional Module & In Subscription Network & In User Profile & In User Interaction \\
\hline PatientsLikeMe & $\begin{array}{l}\text { Diseases } \\
\text { Conditions } \\
\text { Treatments } \\
\text { Symptom categories } \\
\text { Quality of life }\end{array}$ & $\begin{array}{l}\text { Conditions } \\
\text { Symptoms } \\
\text { Treatments } \\
\text { Interests }\end{array}$ & $\begin{array}{l}\text { Conditions } \\
\text { Symptoms } \\
\text { Treatments }\end{array}$ & / \\
\hline HealthBoards & $\begin{array}{l}\text { Types of anxiety } \\
\text { Treatments } \\
\text { A-Z drugs } \\
\text { Disease categories }\end{array}$ & / & $\begin{array}{l}\text { Diagnosis illnesses } \\
\text { Medications and } \\
\text { dosages }\end{array}$ & / \\
\hline WebMed & $\begin{array}{l}\text { Common conditions } \\
\text { Drugs } \\
\text { First aid } \\
\text { Living healthy } \\
\text { Parent guide } \\
\text { Family and pregnancy } \\
\text { Diet and food and fitness } \\
\text { Beauty and balance } \\
\text { Living well }\end{array}$ & / & / & $\begin{array}{l}\text { Symptoms checker } \\
\text { Message boards } \\
\text { Answers } \\
\text { Food and fitness planner } \\
\text { Vaccine } \\
\text { Lupus action plan } \\
\text { Blood glucose } \\
\text { Medicine }\end{array}$ \\
\hline MedHelp & $\begin{array}{l}\text { Disease categories } \\
\text { Conditions }\end{array}$ & Conditions & $\begin{array}{l}\text { Types of disorder } \\
\text { Food diet } \\
\text { Body weight } \\
\text { Shape } \\
\text { Diabetes }\end{array}$ & $\begin{array}{l}\text { Disease trackers } \\
\text { Baby growth } \\
\text { Basal metabolic rate } \\
\text { Body mass index } \\
\text { Burned calories } \\
\text { Diabetes risks } \\
\text { Nutrition search } \\
\text { Ovulations } \\
\text { Pregnancy due }\end{array}$ \\
\hline DailyStrength & Disease categories & Disease categories & / & I \\
\hline HealthUnlocked & Actions of treatments & Disease information & l & / \\
\hline
\end{tabular}

\subsection{Measurement for Effective OHCs}

OHCs are established to connect many online patients to medical experts. In such social networks of online health, a driving force is the homophily phenomenon [36]. However, OHCs possess distinctive features in comparison to conventional health-related websites. Studies validated that the potential utility of $\mathrm{OHCs}$ lies in their ability to promote patient-centred care $[37,38]$. Understanding proper measurement for successful OHCs is important for developing evaluation instruments for OHCs.

However, the social relationship among online patients is not the mere cause of patients' behavioural changes. The recall and attitudes of people with low health literacy can be improved when online health communication contains information that is not cognitively demanding and easily imagined [39]. Improving health literacy is an important means to enhance the effective knowledge seeking in OHCs only when the knowledge-support ability of OHCs enable such communities to do so. For instance, an online patient with high health literacy desiring to obtain information from an $\mathrm{OHC}$ may fail when the OHC is designed poorly and does not offer effective searching tools and results. In the study of nonpsychotic chronic mental illness, problems in providing community care to patients can be identified as belonging to five categories, namely patients, professionals, their interactions, family and social system and mental health systems, which can improve diagnosis and patient care [40]. These factors are important for our study. Information from social and medical knowledge renders $\mathrm{OHCs}$ an inseparable part of daily chronic disease management [41]. Table 2 summarizes the different functions among the six typical OHCs, thereby giving an overview of current OHCs. 
Table 2. Summary of the effective functions in six typical OHCs.

\begin{tabular}{|c|c|c|}
\hline $\mathrm{OHC}$ & Main Modules It Has & What Patients Can Do \\
\hline PatientsLikeMe & $\begin{array}{l}\text { Patient/condition/treatment/symptom, } \\
\text { search module, } \\
\text { Research participation module }\end{array}$ & $\begin{array}{l}\text { Update patients' own profile (hospitalization, } \\
\text { laboratory tests, mood maps, charts, journals, } \\
\text { conditions, symptoms, treatments, quality of life } \\
\text { and weight); browse other patients' journal and } \\
\text { charts; review; find clinical trials; activity trackers; } \\
\text { doctor visit sheet; care teams and patients }\end{array}$ \\
\hline HealthBoards & $\begin{array}{l}\text { Health centres (only anxiety), } \\
\text { Message boards, } \\
\text { Drug talks, } \\
\text { Blogs }\end{array}$ & $\begin{array}{l}\text { Update profile, browse types of anxiety, new post, } \\
\text { find a board, search drug talks, search blogs }\end{array}$ \\
\hline MedHelp & $\begin{array}{l}\text { Communities/conditions, search modules, } \\
\text { Heath tools }\end{array}$ & $\begin{array}{l}\text { Update profile, mobile applications for tracker, } \\
\text { health charts, overview of communities and } \\
\text { forums relevant to specific diseases, posts and } \\
\text { articles on specific diseases }\end{array}$ \\
\hline DailyStrength & $\begin{array}{l}\text { Support groups, } \\
\text { Help/FAQ, } \\
\text { Critical resources, } \\
\text { ShareCare }\end{array}$ & $\begin{array}{l}\text { New post, search blogs, browse members, browse } \\
\text { most popular/recommended/trending groups }\end{array}$ \\
\hline WebMed & $\begin{array}{l}\text { Health A-Z, } \\
\text { Drugs and supplements, } \\
\text { Living healthy, } \\
\text { Family and pregnancy, } \\
\text { News and experts }\end{array}$ & $\begin{array}{l}\text { Search topics relevant to health A-Z; check } \\
\text { symptoms; find a doctor; find lowest drug prices; } \\
\text { search drugs and medicines A-Z, as well as } \\
\text { browse latest drug news; recipe finders, foot } \\
\text { calorie counters, fitness calorie counters, calcium } \\
\text { counters, food and fitness planners and portion } \\
\text { size plates }\end{array}$ \\
\hline HealthUnlocked & $\begin{array}{l}\text { Drug-, condition- and wellness-related } \\
\text { community search }\end{array}$ & $\begin{array}{l}\text { Find communities relevant to your conditions; } \\
\text { browse posts, polls, followers and basic } \\
\text { introduction of specific communities; browse } \\
\text { health topics in common drugs, condition } \\
\text { communities, and wellness communities; share } \\
\text { experiences and follow patients like you }\end{array}$ \\
\hline
\end{tabular}

\subsection{Information Availability}

We initially examined the information availability of 100 health-related websites by applying HC/HIT-8.1 and HC/HIT-8.2 evaluation instruments. To examine the proposed criteria of OHCs, we adopted nine criteria from HC/HIT-8.1 evaluation instruments. Table 3 shows the summarized evaluation results.

Among the selected websites in Table 3, more than half (58\%) are explicitly devoted to commercial purposes. Moreover, $66 \%$ provide clear missions or aims to help online patients. The statements of privacy (92\%) and terms of use (98\%) are widely included in existing websites, indicating that most OHCs pay attention to protection of patient privacy. Only $32 \%$ are comprehensive websites that provide various services, whereas $29 \%$ focus only on a single disorder. Moreover, $25 \%$ of the websites allow users to establish user profiles, but only $11 \%$ of these resemble a social platform that supports online patients. Moreover, $42 \%$ of OHCs enable knowledge discovery. The evaluation of an effective $\mathrm{OHC}$ based on the selected nine criteria is presented in the last nine rows of Table 3. The estimated percentages of the required criteria reveal how the selected websites support online patients in improving the latter's ability in disease management and prevention. Figure 3 illustrates the relation of the percentages of compliant websites to the number of required criteria.

Figure 3 also shows that $46 \%$ of the websites fulfil four or five of the required criteria for an excellent OHC. The percentages of websites fulfilling two and three criteria are $7 \%$ and $13 \%$, respectively. Approximately $31 \%$ involved six or seven criteria. In sum, most websites meet four to six out of the total nine criteria, although they still lack several capabilities in the design of health-related websites to support the improved services for online patients. 
Table 3. Estimated percentages of websites in compliance to Health Communication and Health Information Technology (HC/HIT)-8.1 and required criteria of OHCs.

\begin{tabular}{lccc}
\hline \multicolumn{1}{c}{ Criterion } & N & Count & Percent (\%) \\
\hline Terms of use & 100 & 98 & 98 \\
Privacy & 100 & 92 & 92 \\
Contents related to health-care & 100 & 89 & 89 \\
Information recommendation & 100 & 88 & 88 \\
Social functions & 100 & 84 & 84 \\
Mission to improve health literacy & 100 & 70 & 70 \\
Mission or purpose & 100 & 66 & 66 \\
Contents by doctors or patients & 100 & 66 & 66 \\
Open subscription network & 100 & 59 & 59 \\
Commercial purpose & 100 & 58 & 58 \\
Feedback (form) & 100 & 49 & 49 \\
Knowledge directory & 100 & 42 & 42 \\
Heath-related decision making & 100 & 33 & 33 \\
Comprehensive websites & 100 & 32 & 32 \\
Disease-specific websites & 100 & 29 & 29 \\
Commercial introduction & 100 & 24 & 24 \\
Social websites & 100 & 11 & 11 \\
Patients' charts and journals & 100 & 3 & 3 \\
Statistical results of patient-reported outcomes & 100 & 1 & 1 \\
\hline
\end{tabular}

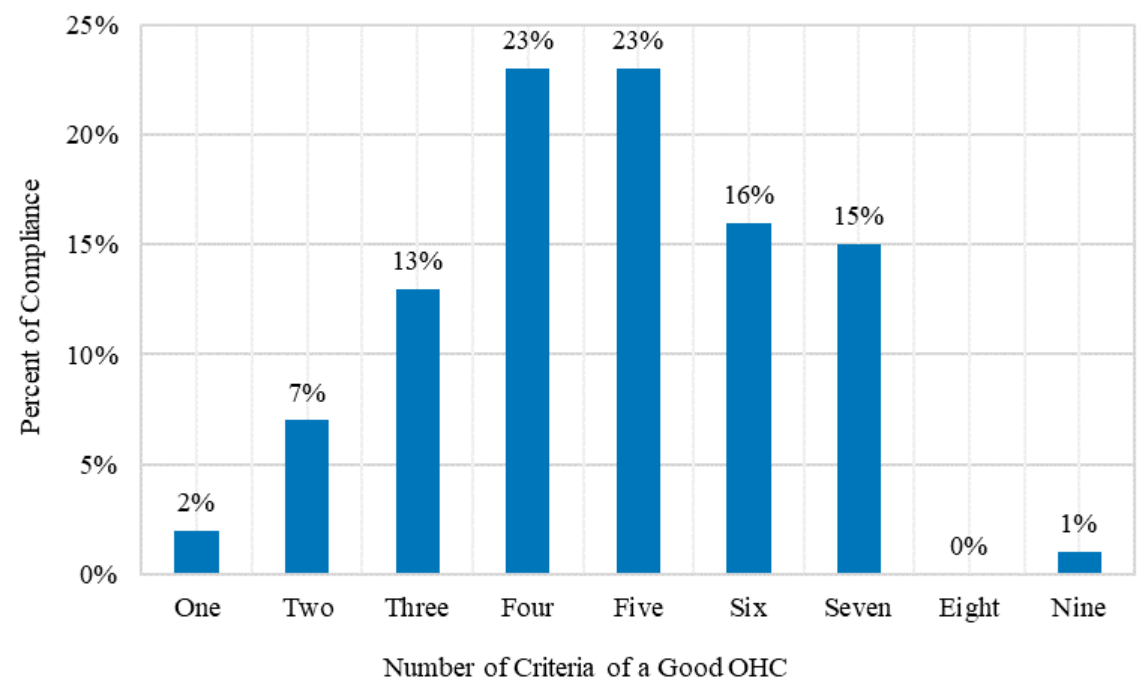

Figure 3. Percentage of compliant websites and the number of reliability criteria.

\subsection{User Availability}

We apply HC/HIT-8.2 to evaluate the user availability of the selected websites. This instrument is also employed to verify the availability of social functions in such websites. Figure 4 shows that only $33 \%$ of the websites have proper social functions, and nearly a third do not facilitate social functions. Table 4 (site design), Table 5 (information architecture) and Table 6 (content design) exhibit the evaluation results of HC/HIT-8.2. 


\section{Convenience in user intreaction}

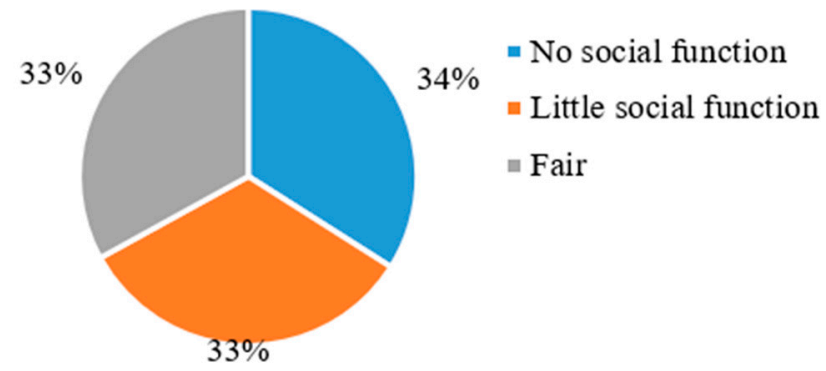

Figure 4. Percentage of websites in terms of convenience in user interaction.

Table 4. Estimated percentages of websites in compliance with the criterion of site design.

\begin{tabular}{lcc}
\hline Criterion & Average Percent (\%) & Average Score \\
\hline 1. Provide clear feedback signals for actions & 98.50 & 3.925 \\
2. Make clickable elements evident & 99.30 & 3.870 \\
3. Use conventional interaction elements & 99.30 & 3.795 \\
4. Minimize vertical scrolling & 93.00 & 3.740 \\
5. Offer a functional home page & 85.30 & 3.680 \\
6. Provide clear feedback signals for actions & 73.30 & 3.230 \\
7. Ensure that the back button behaves predictably & 69.00 & 3.050 \\
8. Ensure site is accessible for users with disabilities & 56.00 & 2.620 \\
and uses elements of 508 compliance & 37.00 & 2.090 \\
9. Incorporate multimedia & & \\
\hline
\end{tabular}

On the basis of these tables, we conclude that, for most OHCs, user availability is not an important issue because most criteria are evidently higher than $90 \%$. This result verifies that the websites are designed sufficiently to support user-centred services. However, certain criteria remain noteworthy. For instance, Criterion 8 holds that only $56 \%$ of the websites provide certain support for disabilities. Moreover, the frequency of multimedia use resource is low in such websites (37\%), and the lack of multimedia resources negatively affects user usability. Moreover, $54 \%$ of the websites provide search functions that include automatic keyword correction and prediction. For Criterion 17, only 59 OHCs are equipped to adopt users' language and minimize jargon and technical terms. These criteria are the most important indicators for enhancing user usability and social connection establishment.

Table 5. Estimated percentages of websites in compliance with the criterion of information architecture.

\begin{tabular}{lcc}
\hline Criterion & Average Percent (\%) & Average Score \\
\hline 10. Ensure texts and background colours contrast & 100.00 & 3.945 \\
11. Present a clear visual hierarchy & 98.50 & 3.858 \\
12. Visually group-related topics & 95.70 & 3.820 \\
13. Make elements on the page easy to read & 99.30 & 3.790 \\
14. Make pages easy to skim or scan & 95.00 & 3.780 \\
15. Clearly label content categories & 94.00 & 3.765 \\
16. Provide easy search functionality & 54.00 & 2.568 \\
\hline
\end{tabular}

Table 6. Estimated percentages of websites in compliance with the criterion of content design.

\begin{tabular}{lcc}
\hline Criterion & Average Percent (\%) & Average Score \\
\hline 17. Use users' language; minimize jargon and technical terms & 59.00 & 3.290 \\
18. Allow for interaction with the content & 82.00 & 3.260 \\
19. Focus the writing on audience and purpose & 81.50 & 3.193 \\
\hline
\end{tabular}




\subsection{Knowledge Usability}

We also employ the third evaluation instrument (see Supplementary Materials) to explore how knowledge usability is integrated in OHCs. Figures 5-7 show the key metrics evaluating knowledge usability in the selected OHCs, respectively. Table 7 presents the other evaluation results of 100 health-related websites according to the response of website reviewers. Among the websites, $23 \%$ have the main purposes of educational and academic, $13 \%$ focus on symptom improvement and $20 \%$ emphasize the establishment of social connection as shown in Figure 6. However, $19 \%$ mainly include commercial product introduction.

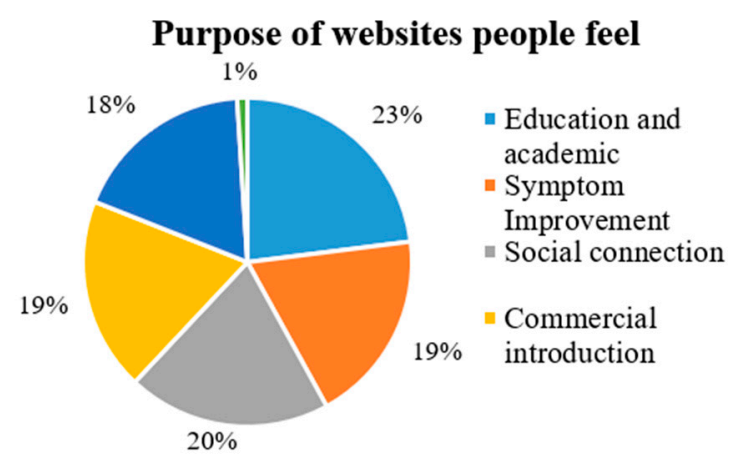

Figure 5. Percentage of the purpose of websites people feel.

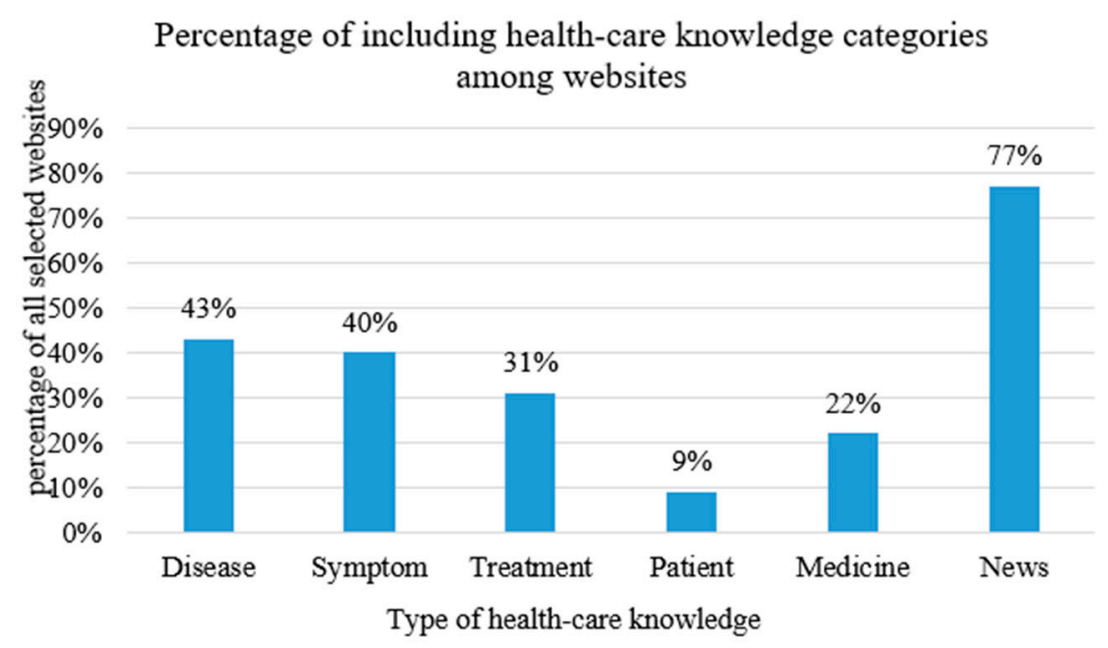

Figure 6. Percentage of including health-care knowledge categories among websites.

\section{Degree of knowledge support}

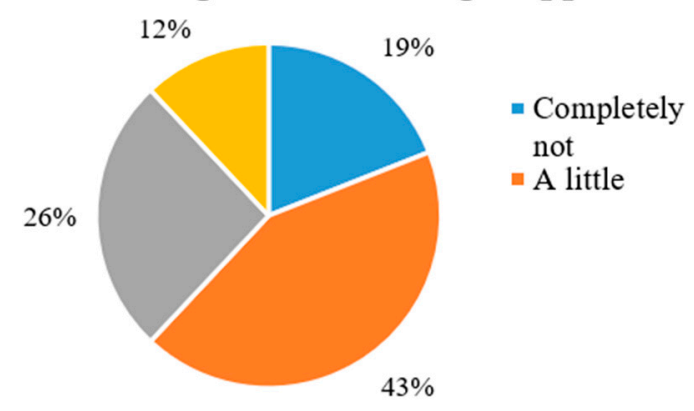

Figure 7. Degree of knowledge support in OHCs. 
Table 7. Evaluation results of 100 health-related websites by investigating how domain knowledge affects OHCs.

\begin{tabular}{lc}
\hline Criterion & Percentage \\
\hline It has a health-related news list & $76 \%$ \\
It has a sharing function to help share their web pages & $71 \%$ \\
It has relevant topics in the home page & $50 \%$ \\
It has basic social functions like posting and commenting & $49 \%$ \\
Knowledge categories have subcategories & $41 \%$ \\
Finding information is convenient for patients & $39 \%$ \\
The main goal of the site is to provide social services & $35 \%$ \\
It provides details of specific biomedical terms and topics & $31 \%$ \\
It has an open subscription network & $28 \%$ \\
It has the function of "find doctors" or "find experts" & $25 \%$ \\
It has certain knowledge graphs connecting different concepts & $23 \%$ \\
It has health evaluation tools & $15 \%$ \\
It has a research support function & $14 \%$ \\
It has hyperlinks to external health-related websites & $12 \%$ \\
It has a patient searching function & $10 \%$ \\
It has certain charts to show the changes of health conditions & $10 \%$ \\
It provides summarized results on the basis of patient-reported data & $7 \%$ \\
It uses codes of terminology from health-care domain knowledge & $1 \%$ \\
\hline
\end{tabular}

Figure 6 depicts that $43 \%, 30 \%, 31 \%$ and $22 \%$ of the 100 health-related websites contain lists of diseases, symptoms, treatments and drugs, respectively. Only 9\% publicly reveal their involved patient list. Figure 7 shows that $43 \%$ of the websites illustrate a low degree of knowledge support for patients. These OHCs still lack the integration of the open subscription network, and searching for other patients' information for a reference remains a challenge for patients. Most sites with knowledge categories provide subcategories to further support patients in their information finding. Table 7 illustrates further results. Only $4 \%$ offer their data for medical company research on improving medical products. Approximately $15 \%$ provide health-care evaluation tools that help patients self-evaluate their health conditions and thus alleviate their symptoms. None of the OHCs use relevant biomedical terminology or controlled vocabularies. Only $31 \%$ provide details of specific biomedical terms and topics. Moreover, $23 \%$ provide knowledge graphs that connect different topics; $76 \%$ include a health-related news list; and $18 \%$ mainly include health-related news. Websites that mainly aim to provide social services comprised $35 \%$ of the studied sites. In our investigation, almost $100 \%$ of the websites' target users are patients. Among these sites, $5 \%$ are specifically allotted to doctors, whereas $42 \%$ are devoted to experts. Moreover, $28 \%$ percent involve open subscription networks, which provide further support to patients' interactions. Only $10 \%$ of the sites offer patient search functions, and $10 \%$ utilize charts and journals to show the changes of patients' health condition.

\section{Discussion}

We have conducted a descriptive study to examine the existing OHCs in terms of enhancing online patient support. For the identification of successful OHCs, criteria for selecting OHCs are proposed. Three evaluation instruments are used to analyse the selected 100 health-related websites in the review process. This section discusses our findings based on the evaluation results of our instruments above for evaluating information availability, user availability and knowledge usability in OHCs.

Successful OHCs provide useful health-related information and effective modules of health-data management to support online patients [42]. Considering the investigation results of six typical OHCs in Tables 1 and 2, we argue that health conditions of chronic patients can be improved by OHCs through three approaches, namely full journals and condition charts, open subscription networks and health-care domain knowledge in PatientsLikeMe [43]. First, journals and charts allow patients to record their own physiological and psychological health information at any place and 
time. This approach provides massive medical and health-care data for further medical research. These accumulated data are highly useful references for other patients and help the analysis system provide improved services. Second, an open subscription network is a key approach for assisting chronic patients. This service publicizes transparent and open relationships of patients' preferences to enhance patients' self-management support [44]. This information then inspires online patients to follow and subscribe to other patients' profiles with similar experiences and share private health-care data in a developed social network. Third, health-care knowledge renders OHCs distinct from other general social platforms. In PatientsLikeMe, many authoritative definitions and helpful tips of medical concepts are provided. Such knowledge includes the categories of treatments listed in the Treatment Module. The knowledge is also useful to improve knowledge-based services for chronic patients, especially for those without proper medical education.

Evaluation Instruments 1 and 2, which are based on HC/HIT-8.1 and HC/HIT-8.2, respectively, assess the availability of the selected 100 health-related websites. With the development of website design, most websites are thoroughly designed to support online users in terms of user experience. For instance, $84 \%$ of the sites facilitate social functions, and $88 \%$ of investigated websites enable information recommendation. This first finding indicates that a main problem hindering the alleviation of online patients' conditions is irrelevant to their user experience. In the extended investigation based on HC/HIT-8.1, only 33 websites provide health-related decision-making services to online patients. Three of the websites merely facilitate functions of patients' charts and journals to support effective management of health data. Among the sites, $46 \%$ satisfy four or five criteria. Few of these sites offer statistical results of patient-report outcomes. Thus, the second finding also indicates that most existing health websites cannot assist patients in making effective health decisions, not to mention properly using health-care knowledge in OHCs. Tables 4-6 illustrate the results evaluating site design, information architecture and content design, respectively, revealing that most health-related websites satisfy HC/HIT-8. Results also confirm that sites' user experience is sufficient, but not the main influencing factor for social interaction. The third evaluation instrument evaluates the knowledge usability of these websites. Great information reliability and web usability result in websites' high effectiveness in enhancing online patients' user experience and, eventually, patients' self-management ability [45]. However, with the development of the Internet, a well-designed health-related website still requires further involvement of health-care knowledge to influence social interaction effectively among patients in OHCs, given that OHCs are composed of online social networks involved with patients and medical experts with different health literacy [46]. Moreover, patients are motivated to seek professional knowledge and advice from online communities.

However, although our research provides interesting insights into studying how to improve existing OHCs with knowledge support, certain limitations still exist. First, we have selected 100 health-related websites that cannot represent all OHCs on the Internet. Still, we carefully select the websites based on the Internet traffic statistics provided by third-party Internet companies such as Alexa [47]. Second, the accuracy of evaluation results relies on the reviewers we invited, and sometimes, errors are inevitable. In our research, the selected reviewers for solving this problem are required to review each website at least twice. Finally, yet importantly, we improved our evaluation instruments based on HC/HIT-8.1 and HC/HIT-8.2 by extending the investigation of knowledge support. Moreover, the usability of such websites can also be measured with measures like the system usability scale [48]. The metrics in these instruments can be subjective, but can also be easily modified according to other needs of evaluation in practical use.

\section{Conclusions}

Our descriptive study on 100 health-related websites concludes that most existing OHCs do not effectively utilize health-related domain knowledge in helping online patients seek proper health information. Such OHCs also cannot enhance social interaction among online patients. Criteria analyses of a successful $\mathrm{OHC}$ among the existing websites help service providers upgrade their services from 
the perspective of information systems with knowledge support. The main findings of the three evaluation instruments confirmed that $\mathrm{OHC}$ designers should consider OHCs' information system as a socio-knowledge system instead of a socioeconomic system. This study also affirms domain knowledge as an essential contributor to improve knowledge-based services in OHCs. For service providers and designers of $\mathrm{OHCs}$, using health-care knowledge enhances social interaction between patients and information systems. For online patients with low health literacy, OHCs with knowledge support have a great influence on improving patients' online behaviours and self-management ability.

Supplementary Materials: The following are available online at http:/ /www.mdpi.com/2078-2489/9/8/199/s1: Table S1: One-hundred health-related websites in our descriptive study; Evaluation instrument 3: Influence of domain knowledge on social network in OHCs.

Author Contributions: Investigation, K.L. Methodology, D.C. Supervision, R.Z. Writing, review and editing, L.H.

Funding: This work was partially supported by a key project of National Natural Science Foundation of China under Grant Number 71532002.

Conflicts of Interest: The authors declare no conflict of interest.

\section{References}

1. Gray, C.S.; Miller, D.; Kuluski, K.; Cott, C. Trying eHealth tools to patient needs: Exploring the use of eHealth for community-dwelling patients with complex chronic disease and disability. JMIR Res. Protoc. 2014, 3, e67. [CrossRef] [PubMed]

2. Willis, E.; Royne, M.B. Online health communities and chronic disease self-management. Health Commun. 2016, 32, 269-278. [CrossRef] [PubMed]

3. Cameron, J.; Rhodes, K.L.; Ski, C.F.; Thompson, D.R. Careers' views on patient self-care in chronic heart failure. J. Nurs. 2016, 25, 144-152.

4. Allen, C.; Vassilev, I.; Kennedy, A.; Rogers, A. Long-term condition self-management support in online communities: A meta-synthesis of qualitative papers. J. Med. Internet Res. 2016, 18, e61. [CrossRef] [PubMed]

5. Dobkin, P.L.; Boothroyd, L.J. Organizing health services for patients with chronic pain: When there is a will there is a way. Pain Med. 2008, 9, 881-889. [CrossRef] [PubMed]

6. Wicks, P.; Massagli, M.; Frost, J.; Brownstein, C.; Okun, S.; Vaughan, T.; Bradley, R.; Heywood, J. Sharing health data for better outcomes on PatientsLikeMe. J. Med. Internet Res. 2017, 12, e19. [CrossRef] [PubMed]

7. James, D.C.; Harville, C. eHealth Literacy, Online help-seeking behavior, and willingness to participate in mHealth chronic disease research among African Americans, Florida, 2014-2015. Prev. Chron. Dis. 2016, 13, E156. [CrossRef] [PubMed]

8. Mccloud, R.F.; Okechukwu, C.A.; Sorensen, G.; Viswanath, K. Beyond access: Barriers to internet health information seeking among the urban poor. J. Am. Med. Inf. Assoc. 2016, 23, 1053-1059. [CrossRef] [PubMed]

9. Kazmer, M.M.; Lustria, M.L.A.; Cortese, J.; Burnett, G.; Kim, J.H. Distributed knowledge in an online patient support community: Authority and discovery. J. Am. Infom. Sci. Technol. 2014, 65, 1319-1334. [CrossRef]

10. Huh, J.; Kwon, B.C.; Kim, S.H.; Lee, S.; Choo, J.; Kim, J.; Choi, M.J.; Yi, J.S. Personas in online health communities. J. Biomed. Inf. 2016, 63, 212-225. [CrossRef] [PubMed]

11. Xiang, J.; Stanley, S.J. From online to offline: Exploring the role of e-health consumption, patient involvement, and patient-centered communication on perceptions of health care quality. Comput. Hum. Behav. 2017, 70, 446-452. [CrossRef]

12. Juth, V.; Smyth, J.M.; Santuzzi, A.M. How do you feel? self-esteem predicts affect, stress, social interaction, and symptom severity during daily life in patients with chronic illness. J. Health Psychol. 2008, 13, 884-894. [CrossRef] [PubMed]

13. Rzeszutek, M.; Oniszczenko, W.; Schier, K.; BiernatKaluza, E.; Gasik, R. Temperament traits, social support, and trauma symptoms among HIV/AIDS and chronic pain patients. Int. J. Clin. Health Psychol. 2016, 16, 137-146. [CrossRef]

14. Morrison, E.J.; Flynn, J.M.; Jones, J.; Byrd, J.C.; Andersen, B.L. Individual differences in physical symptom burden and psychological responses in individuals with chronic lymphocytic leukemia. Ann. Hematol. 2016, 95, 1989-1997. [CrossRef] [PubMed] 
15. Möller-Leimkühler, A.M.; Wiesheu, A. Caregiver burden in chronic mental illness: The role of patient and caregiver characteristics. Eur. Arch. Psychiatry Clin. Neurosci. 2012, 262, 157-166. [CrossRef] [PubMed]

16. Diviani, N.; Van, D.; Meppelink, C.S.; Weert, J.C. Exploring the role of health literacy in the evaluation of online health information: Insights from a mixed-methods study. Patient Educ. Couns. 2016, 99, 1017-1025. [CrossRef] [PubMed]

17. Zisook, S.; Tal, I.; Weingart, K.; Hicks, P.; Davis, L.L.; Chen, P.; Yoon, J.; Johnson, G.R.; Vertrees, J.E.; et al. Characteristics of US veteran patients with major depressive disorder who require "next-step" treatments: A VAST-D report. J. Affect. Disord. 2016, 206, 232-240. [CrossRef] [PubMed]

18. Joensen, L.E.; Almdal, T.P.; Willaing, I. Associations between patient characteristics, social relations, diabetes management, quality of life, glycaemic control and emotional burden in Type 1 diabetes. Primary Care Diabetes 2015, 10, 41-50.

19. Gordon, K.; Smith, F.; Dhillon, S. Effective chronic disease management: Patients' perspectives on medication-related problems. Patient Educ. Counsel. 2007, 65, 407-415. [CrossRef] [PubMed]

20. Allen, M.; Iezzoni, L.I.; Huang, A.; Huang, L.; Leveille, S.G. Improving patient-clinician communication about chronic conditions: Description of an internet-based nurse E-coach intervention. Nurs. Res. 2008, 57, 107-112. [CrossRef] [PubMed]

21. Gaikwad, M.; Vanlint, S.; Moseley, G.L.; Mittinty, M.N.; Stocks, N. Understanding patient perspectives on management of their chronic pain-Online survey protocol. J. Pain Res. 2016, 10, 31-35. [CrossRef] [PubMed]

22. Diviani, N.; Putte, B.; Giani, S.; Weert, J. Low health literacy and evaluation of online health information: A systematic review of the literature. J. Med. Internet Res. 2015, 17, e112. [CrossRef] [PubMed]

23. Theresa, D.; Jordan, B.; Harris, L.M.; Wu, H.; Williams, H.S. Making quality health websites a national public health priority: Toward quality standards. J. Med. Internet Res. 2016, 18, e211.

24. Yan, Z.; Wang, T.; Chen, Y.; Zhang, H. Knowledge sharing in online health communities: A social exchange theory perspective. Inform. Manag. 2016, 53, 643-653. [CrossRef]

25. Mohammad, H.; Woensel, W.V.; Abidi, R.S.; Abidi, S.S. Semantics-based plausible reasoning to extend the knowledge coverage of medical knowledge bases for improved clinical decision support. Biodata Min. 2017, 10,7 .

26. Wicks, P.; Vaughan, T.E.; Massagli, M.P.; Heywood, J. Accelerated clinical discovery using self-reported patient data collected online and a patient-matching algorithm. Nat. Biotechnol. 2011, 29, 411-414. [CrossRef] [PubMed]

27. Wiering, B.; De, B.D.; Dlnoij, D. Patient involvement in the development of patient-reported outcome measures: A scoping review. Health Expect. 2017, 20, 11-23. [CrossRef] [PubMed]

28. Kim, H.; Xie, B. Health literacy in the eHealth era: A systematic review of the literature. Patient Educ. Counsel. 2017, 100, 1073-1082. [CrossRef] [PubMed]

29. Protheroe, J.; Whittle, R.; Bartlam, B.; Estacio, E.V.; Clark, L.; Kurth, J. Health literacy, associated lifestyle and demographic factors in adult population of an English city: A cross-sectional survey. Health Expect. 2017, 20, 112-119. [CrossRef] [PubMed]

30. Quinn, S.; Bond, R.; Nugent, C. Quantifying health literacy and eHealth literacy using existing instruments and browser-based software for tracking online health information seeking behavior. Comput. Hum. Behav. 2017, 69, 256-267. [CrossRef]

31. Gutierrez, N.; Kindratt, T.B.; Pagels, P.; Foster, P.; Gimpel, N.E. Health literacy, health information seeking behaviors and internet use among patients attending a private and public clinic in the same geographic area. J. Commun. Health 2014, 39, 83-89. [CrossRef] [PubMed]

32. Fu, Y.; Yu, G.; Mcnichol, K.; Marczewski, K.; Closs, S.J. The effects of patient-professional partnerships on the self-management and health outcomes for patients with chronic back pain: A quasi-experimental study. Int. J. Nurs. Stud. 2016, 59, 197. [CrossRef] [PubMed]

33. Tommasetti, A.; Troisi, O.; Cosimato, S. Patient empowerment and health online community: Two ways to give the new viability doctor-patient relationship. J. Mol. Struct. 2014, 193, 295-300.

34. Van der Eijk, M.; Faber, M.J.; Aarts, J.W.; Kremer, J.A.; Munneke, M.; Bloem, B.R. Using online health communities to deliver patient-centered care to people with chronic conditions. J. Med. Internet Res. 2013, 15, e115. [CrossRef] [PubMed]

35. Online Health Communities. Available online: https://en.wikipedia.org/wiki/Online_health_communities (accessed on 21 July 2018). 
36. Yan, L.L.; Peng, J.; Tan, Y. Network dynamics: How can we find patients like us? Inf. Syst. Res. 2015, 26, 496-512. [CrossRef]

37. Amann, J.; Zanini, C.; Rubinelli, S. What online user innovation communities can teach us about capturing the experiences of patients living with chronic health conditions: A scoping review. PLoS ONE 2016, 11, e0156175. [CrossRef] [PubMed]

38. Rozenblum, R.; Bates, D.W. Patient-centred healthcare, social media and the internet: the perfect storm? BMJ Qual. Saf. 2013, 22, 183. [CrossRef] [PubMed]

39. Meppelink, C.S.; Smit, E.G.; Diviani, N.; Weert, J. Health literacy and online health information processing: Uinraveling the underlying mechanisms. J. Health Commun. 2017, 21, 109-120. [CrossRef] [PubMed]

40. Koekkoek, B.; Van, M.B.; Schene, A.; Hutschemaekers, G. A Delphi study of problems in providing community care to patients with nonpsychotic chronic mental illness. Psychiatr. Serv. 2009, 60, 694-697. [CrossRef] [PubMed]

41. Magnezi, R.; Bergman, D.; Grosberg, D. Online activity and participation in treatment affects the perceived efficacy of social health networks among patients with chronic illness. J. Med. Internet Res. 2014, 16, e12. [CrossRef] [PubMed]

42. Centola, D.; Van, D.R.A. Choosing your network: Social preferences in an online health community. Soc. Sci. Med. 2015, 125, 19-31. [CrossRef] [PubMed]

43. Naujoks, C.; Olson, M.; Simsek, D.; Vulpillieres, F.; Vo, P.; Kendall, K.R.; Cerrato, D. How do Migraines Impact Patient Day-To-Day life? An Exploratory Analysis of Patient Reported Data From The Patientslikeme Community. Val. Health 2016, 19, A438-A439. [CrossRef]

44. Ammerlaan, J.W.; Van, O.H.; De, B.N.; Scholtus, L.; Kruize, A.A.; Bijlsma, J.W.; Geenen, R. Preferences and needs of patients with a rheumatic disease regarding the structure and content of online self-management support. Patient Educ. Couns. 2017, 100, 501-508. [CrossRef] [PubMed]

45. Spiers, H.; Amin, N.; Lakhani, R.; Martin, A.J.; Patel, P.M. Assessing Readability and Reliability of Online Patient Information Regarding Vestibular Schwannoma. Otol. Neurotol. 2017, 38, e470-e475. [CrossRef] [PubMed]

46. Bosslet, G.T.; Torke, A.M.; Hickman, S.E.; Terry, C.L.; Helft, P.R. The patient-doctor relationship and online social networks: Results of a national survey. J. Gen. Intern. Med. 2012, 27, 404. [CrossRef] [PubMed]

47. Alex Top 500 Global Sites. Available online: https:/ / www.alexa.com/topsites (accessed on 28 July 2018).

48. Lewis, J.R. The System Usability Scale: Past, Present, and Future. Int. J. Hum.-Comput. Interact. 2018, 3, 577-590. [CrossRef] 